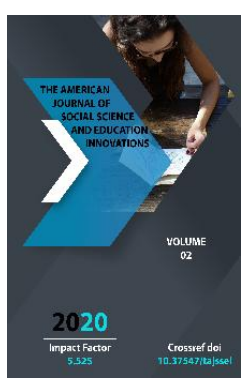

Journal Website: http://usajournalshub.c om/index,php/tajssei

Copyright: Original content from this work may be used under the terms of the creative commons attributes 4.0 licence.

\section{Use Of Historical Materials In Teaching Mathematics In Continuous Education}

\author{
Gulhayo Bakhodirovna Kuzmanova \\ Teacher, Department Of Primary Education And Sports Education, Chirchik State Pedagogical \\ Institute, Uzbekistan
}

\author{
Nurseit Alijan Ogli Beketov \\ Teacher, Department Of Primary Education And Sports Education, Chirchik State Pedagogical \\ Institute, Uzbekistan
}

\title{
ABSTRACT
}

This article is aimed at teaching students historical material in order to give students practical and theoretical knowledge in mathematics lessons in the modern educational process. If we look at the centuries-old history, then it is the duty and duty of every teacher to pass on the national heritage of our ancestors to the younger generation. The works of Al-Khwarizmi, Ibn Sina, Beruni, and Abu Nasr Farobi on mathematics deserve special attention. The works of our great scientists include, in particular, methods for solving equations of that time, the concept of residuals, simple methods of addition, subtraction, multiplication of multi digit numbers, convenient methods for calculating the square of numbers through ancient problems. It is also aimed at further improving the quality of lifelong education, at teaching students to think independently in mathematics lessons, at further strengthening their socio-economic, scientific and technical knowledge in mathematics. In addition, mathematical education in secondary schools will use historical material in the formation of students' scientific and theoretical thinking in the process. If you pay more attention to it, opportunities will expand for educating the student as a person with rich knowledge, inner world, and spiritually mature.

\section{KEYWORDS}

Continuous education, equation, square, remainder, quantity, natural, dirham, number, multiplication, arithmetic, angle, radius, root, mathematics.

\section{INTRODUCTION}

Continuous education is the basis of the system of training, ensuring the socioeconomic development of the Republic of
Uzbekistan, a priority area that meets the economic, social, scientific, technical and cultural needs of the individual and the state. 
Therefore, in today's educational process, the main goal of every science teacher is not only to teach students, but also to apply them in practice, to teach them to think independently, to develop their abilities, and to educate them based on national and universal values. In the process of teaching mathematics in general secondary schools, if the emphasis is placed on the use of historical materials in the formation of scientific and theoretical thinking, the education of students as a person with a rich inner world, opportunities for upbringing as a spiritually mature person will be further expanded..

Today, the main goal of every science teacher is not only to teach students in the educational process, but also to apply them in practice, to teach them to think independently, to develop their abilities, and to educate them based on national and universal values. It is necessary.

In the process of teaching mathematics in general secondary schools, if more attention is paid to the use of historical materials in the formation of scientific and theoretical thinking, the opportunities for educating students as a person rich in knowledge, inner world, spiritually mature will expand.

Today, the process of integration of people and nations is gaining momentum. In this process, the study of our rich scientific heritage is one of the main tasks facing teachers.

\section{LITERATURE ANALYSIS AND METHODOLOGY}

If we look at the history, the unparalleled discoveries made at the Boytul-Hikma in Baghdad and at the Khorezm Mamun Academy have left an indelible mark on history. In particular, we can cite many of our scholars, such as Muhammad ibn Musa alKhwarizmi, Abu Nasr al-Farabi, Abu Rayhan Beruni, Ibn Sina. In their works, they raised the relationship between the teacher and the student to a high level and at the same time paid special attention to such issues as the influence of the individual on the intellect.

We know that Al-Khwarizmi's contribution to the development of mathematics as a science is great. Khorezmi's work "Al-jabr val muqabala" appears before our eyes as a great mathematician. If we translate this work anonymously, "Al jabr" means to restore, "val muqabala" means to oppose. He founded the science of algebra on the basis of al-jabr and muqabala. The play describes logical problems, equations, fractions, as well as the convenience of solving first- and second-order equations according to certain rules and symbols, and gives specific examples of ways to solve this type of equation. For ease of solving this type of equation, it is recommended to study the equations in classes.

1. A class with equal square roots:

$$
\begin{aligned}
& 5 x^{2}=10 \\
& x^{2}=10 \div 5 \text { Hence } \\
& x^{2}=5 \\
& 6 x^{2}=30
\end{aligned}
$$

$$
\begin{gathered}
5 x^{2}=10 \\
5 \cdot 2=10 \\
10=10 \\
6 x^{2}=30
\end{gathered}
$$




$$
\begin{array}{lr}
x^{2}=30 \div 6 \text { Hence } & 6 \cdot 5=30 \\
x^{2}=5 & 30=30
\end{array}
$$

2. A class whose squares are equal to a number:

$$
\begin{array}{cc}
5 x^{2}=80 & 3 x^{2}=27 \\
x^{2}=80 \div 5 \text { Hence } & x^{2}=27 \div 3 \\
x^{2}=16 & x^{2}=9
\end{array}
$$

2. Both roots and squares are equal.

$$
x^{2}+a x+b=c
$$

3. The roots of squares and numbers are equal.

$$
x^{2}+21=10 x
$$

4. Roots and numbers are equal to squares.

$$
3 x+a=x^{2}
$$

He also described the 24 different canonical forms of quadratic and cubic equations. Multiplication of multi-digit numbers is taught in the form of columns on the topic "Multiplication of natural numbers" in mathematics.

For example; $8324 \times 234$ multiply by

$\times 8324$
254
+33296
+24972
16648
1947816

The method of "multiplication in the table" was invented by the Central Asian scientist Abu Jafar Muhammad ibn Muhammad Masriddin at-Tusi (1201-1274).

\begin{tabular}{|l|l|l|l|l|l|}
\hline & 8 & 3 & 2 & 4 & \\
\hline 1 & 6 & 6 & 4 & 8 & 2 \\
\hline 2 & 4 & 9 & 7 & 2 & 3 \\
\hline 3 & 3 & 2 & 9 & 6 & 4 \\
\hline
\end{tabular}

For example, multiplying 8324 by 234 is shown in the table. In the "multiplication in the table" method, divide a rectangle into squares, leaving one square on the right; write the 1st multiplier from the top to the width, and the 2nd multiplier from the right. In practice, the current method is performed from one of the multipliers. The numbers of the special product are not always written in equal digits, but from the right on the horizontal line, one below the other. It is taught that in the formation of the numbers of the product 
sought, it is necessary to add in equal rooms. The sought product is formed by calculating the sum of the numbers of special products on the diagonal of the squares from the right. The numbers of this product are written from the right at the bottom of the table.

\section{Result: 1947816}

Works of Ibn Sina also contain a lot of information on the development of mathematics. Work of Ibn Sina on natural numbers is noteworthy in his treatises on arithmetic and number theory, such as The Wise, Knowledge, and Healing. In the arithmetic section of the book, it is said that when all the numbers in a series of natural numbers are squared, a number equal to one of the numbers 1, 4, 5, 6, 9 is always formed in one of the rooms.

$$
\begin{aligned}
& \text { Indeed } \\
& 11^{2}=11 \times 11=121 \\
& 12^{2}=12 \times 12=144 \\
& 13^{2}=13 \times 13=169 \\
& 14^{2}=14 \times 14=196 \\
& 15^{2}=15 \times 15=225 \\
& 16^{2}=16 \times 16=256
\end{aligned}
$$

Then Ibn Sina describes the example of checking the square of a number by the number 9 in the Indian arithmetic method with the following rules.

1. If a number is divided by 9 and the remainder is 1 or 8 , then the square of such numbers is divided by 9 and remains in the remainder 1 . Let $M$ and $N$ be given numbers. As a rule

$$
\begin{aligned}
& M=9 n+1 \\
& M^{2}=(9 n+1)^{2}=81 n^{2}+18 n+1=9\left(9 n^{2}+2 n\right)+1 \\
& \text { divide by } 9 \text {, the remainder is } 1
\end{aligned}
$$

$$
\mathrm{N}=9 \mathrm{k}+8:
$$

$M^{2}=(9 k+8)^{2}=81 k^{2}+72 k+64=81 k^{2}+72 k+63+1=9(9 k$

$\left.{ }^{2}+8 k+7\right)+1$

$$
9\left(9 k^{2}+8 k+7\right) \text { divide by } 9 \text {, the remainder }
$$
is 1.

2. If the number is divisible by 9 and the remainder is 2 and 7, then the square of such numbers is divisible by 9 and the remainder is always 4 .

3. 3. If the number is divisible by 9 and the remainder is 4 and 5 , then the square of such numbers is divisible by 9 and the remainder is always 7 .

4. If the number is divisible by 9 and the remainder is 3.6 and 9, then the square of such numbers is divisible by 9 and the remainder is always 8 .

\section{RESULTS}

\section{Using Beruni's work in the classroom Examples from Beruni's problems}

The rule of five quantities. Finding an unknown $x$ from the proportion $a: b=c: x$ for three numbers $a, b, c$ is known as the "rule of three quantities". This rule is mentioned in one of the works of our great encyclopedic scholar Abu Rayhan Beruni. Beruni argued that the "rule of three quantities" could be applied when the number of known quantities was 5 , 7, and even 15, 17.

In the process of solving a problem, we explain the essence of the "rule of five".

The case of Abu Rayhan Beruni, If 10 dirham (currency) yields 5 dirham in 2 months, how much profit does 8 dirham bring in 3 months? 


\section{Solution.}

To address this and similar issues, Beruni then provides a rule.

1. Method. 1) The 5 numbers given in the problem are placed as follows:

2. Multiply the numbers in the right column: $8 \cdot 3 \cdot 5$ = 120;

$\begin{array}{cc}10 & 8 \\ 2 & 3 \\ & 5\end{array}$

3. We also multiply the numbers in the left column: $10 \cdot 2=20$;

4. We obtain the ratio of the answers given in 2) and 3):

$$
\frac{120}{20}=6
$$

The unknown requested in the case will be the 6.

Answer: 8 dirham brings 6 dirham in 3 months. 2 - method. 1) Suppose that 8 dirham bring $x$ dirham in 3 months. We place the quantities as follows:

$$
\begin{array}{cc}
10 & 8 \\
2 & 3 \\
5 & x
\end{array}
$$

It is important to note that the dirham must correspond to the dirham, the month to the month

$$
\frac{10}{8} \cdot \frac{2}{3}=\frac{5}{x}
$$

2) We compose this expression:

(In the figure, the numbers in the left column, and in the denominators, the numbers in the right column; an equal sign "," is placed in front of the ratio of the numbers in the last row with unknown $\mathrm{x}$ ).

It is easy to find $x$ from the above equation:

$$
\text { Hence } \mathrm{x}=6 \frac{1}{2} \cdot \frac{1}{3}=\frac{1}{x}
$$

Answer: 6 dirham.
1 - question. How much profit does 1 dirham bring in 2 months? $5 \div 10=\frac{1}{2}$ (dirham).

2 - question. How much profit does 1 dirham bring in 1 month? $1 / 2 \div 2=1 / 4$ (dirham).

3 - question. How much profit does 8 dirham bring in 1 month? $1 / 4 \cdot 8=2$ (dirham). 4 - question. What about 8 dirham in 3 months? $2 \cdot 3=6$ (dirham)

Answer: 6 dirham.

It is also possible to solve the problem more simply by combining questions 1 and 2, 3 and 4.

1 - question. How much profit does 1 dirham bring in 1 month? $5 \div(10 \cdot 2)=\frac{1}{4}($ dirham $)$.

2-question. How much profit does 8 dirham bring in 3 months? $\frac{1}{4} \cdot(8 \cdot 3)=6($ dirham $)$.

\section{DISCUSSION}

\section{(The case of Abu Rayhan Beruni)}

The dimensions of the brick (height, width, height) are 5, 4, 3 units of length, respectively. The price of 30 such bricks is 60 dirham (currency). What is the price of 20 bricks of 8 , 6,2 length units, in dirham?

Solution. Suppose the amount of money you are looking for is $x$ dirham. First, 10 " corresponding " table is drawn and the information given in the problem is placed in the table as follows:

\section{3 - method.}




\begin{tabular}{|l|l|}
\hline 5 & 8 \\
\hline 4 & 6 \\
\hline 3 & 2 \\
\hline 30 & 20 \\
\hline 60 & $x$ \\
\hline
\end{tabular}

Then the following equation is written:

We find an unknown $\mathrm{x}$ in this equation:

$$
\frac{60}{x}=\frac{30}{20} \cdot \frac{3}{2} \cdot \frac{4}{6} \cdot \frac{5}{8}
$$

$x=\frac{60 \cdot 20 \cdot 2 \cdot 6 \cdot 8}{30 \cdot 3 \cdot 4 \cdot 5}$, hence $x=64$ (dirham).

Answer: 64 dirham.

The above solution to the problem belongs to Beruni, and this solution is given in his book, named The Book of Indian Rashiks. ("rashik" means place,):

1. The cost of one brick is 60: $30=2$ (dirham).

2. 2. The size of one brick is $5 \cdot 4 \cdot 3=60$ (kub birlik).

3. 1 cubic unit of brick is $2 / 60=\frac{1}{30}$ (dirham).

4. The size of the second type of brick is $8 \cdot 6 \cdot 2=96$ (kub birlik).

6. One second brick costs $96 / 30$ (dirham).

20 bricks of the second type are $96 / 30 \cdot 20=64$ (dirham).

Answer: 64 dirham.

\section{CONCLUSION}

In short, the contribution of our ancestors to the development of mathematics is the ancient units of measurement, ancient issues to convey to the reader their educational significance and continuous education in the formation of a creative, socially active, spiritually rich person, especially in school mathematics and training of highly qualified competitive personnel.

\section{REFERENCES}

1. A.Amalov "Matematika o'qitishda tarixiy ma'lumotlardan

foydalanish"Tashkent,2005y
2. S.A.Ahmedov,S.Ahmedova "O'rta Osiyoda arifmetika taraqqiyoti va uning o'qitish tarixi“"Tashkent, 1991y 
Doi: https://doi.org/10.37547/tajssei/Volume02Issue09-80

3. Bikbayeva N.U and others "Matematika 2"

- Tashkent: Teacher, 2010y

4. . www.nadlib.uz 